Submitted to Journal of Hydraulic Research, April 18, 2003

\title{
MODELING DOWNSTREAM FINING IN SAND-BED RIVERS II: APPLICATION
}

\author{
Scott Wright \\ Graduate Student, St. Anthony Falls Laboratory, University of Minnesota \\ Currently at: U.S. Geological Survey \\ Placer Hall, 6000 J Street \\ Sacramento CA 95819 \\ 916-278-3031 phone \\ 916-278-3013 fax \\ sawright@usgs.gov
}

Gary Parker

Professor

University of Minnesota

St. Anthony Falls Laboratory

$23^{\text {rd }}$ Ave. SE

Minneapolis, MN 55414 


\begin{abstract}
In this paper the model presented in the companion paper, Wright and Parker (submitted) is applied to a generic river reach typical of a large, sand-bed river flowing into the ocean in order to investigate the mechanisms controlling longitudinal profile development and downstream fining. Three mechanisms which drive downstream fining are studied: a delta prograding into standing water, sea-level rise, and tectonic subsidence. Various rates of sea-level rise (typical of the late Holocene) and tectonic subsidence are modeled in order to quantify their effects on the degree of profile concavity and downstream fining. Also, several other physical mechanisms which may affect fining are studied, including the relative importance of the suspended versus bed load, the effect of the loss of sediment overbank, and the influence of the delta bottomset slope. Finally, sensitivity analysis is used to show that the grain-size distribution at the interface between the active layer and substrate has a significant effect on downstream fining.
\end{abstract}

\title{
1 Introduction
}

In the companion paper (Wright and Parker, submitted), a formulation was presented for modeling the development of the longitudinal profile and downstream variation in bed sediment characteristics of large, low-slope sand-bed rivers. Many rivers exhibit a downstream decrease in bed slope and bed sediment median grain-diameter in the downstream direction, as illustrated in Figures 1 and 2 of the companion paper (Wright and Parker, submitted). In this paper, the model is applied to conditions typical of sand-bed rivers flowing into the ocean in order to study the mechanisms driving the phenomena, and the processes controlling the strength of downstream fining and profile concavity.

The model formulation contains several assumptions which may limit its applicability to the past 5,000 years of relatively stable sea-level. According to the model of Holocene river development promoted by Blum and Tornqvist (2000) and Aslan and Autin (1999), based on data from the Rhine-Meuse, Texas Gulf Coast, and Lower Mississippi Valley, rapid sea-level rise ( $10 \mathrm{~mm} / \mathrm{yr})$ from about $20 \mathrm{kry}$ B.P. to $5 \mathrm{kyr}$ B.P. was accompanied by a rapidly aggrading floodplain with multi-channel streams, frequent 
avulsion, crevasse splays, and poorly drained backswamps. The past 5,000 years of little or no sea-level rise $(\sim 1 \mathrm{~mm} / \mathrm{yr})$ lead to slower rates of floodplain aggradation, meanderbelt development and overbank deposition. The model formulation is applicable to the period of slower aggradation of the past 5,000 years only for several reasons. First, flow is assumed in a single channel with no floodplain, which leads to the implicit assumption that overbank floodplain deposition keeps pace with channel aggradation. The single channel assumption is not directly valid for the period of multi-channel flows. The overbank deposition assumption is not valid for the conditions of rapid sea-level rise when the floodplain was being built by channel avulsion, crevasse splays, and the filling of poorly-drained floodplain lakes. Also, discharge and sediment load conditions during glacial melting likely differed significantly from loads during stable sea-level in such rivers as the Mississippi. Finally, the closure relationships for hydraulic resistance and sediment transport capacity were developed empirically from data for modern, singlethread, meandering, sand-bed rivers. Thus these relationships may not be applicable to the avulsing, multi-channel streams of the period of rapid sea-level rise.

The strategy for model simulation is to study the mechanisms controlling the development of the longitudinal profile and downstream fining in a generalized manner. Thus, the model was applied to a generic river reach with conditions typical of large, suspension-dominated sand-bed rivers flowing to the ocean. The generic river reach was subjected to several forcing mechanisms that drive fining, including a prograding delta, sea-level rise, and subsidence. Each mechanism drives aggradation accompanied by size selective transport which leads to a concave upward profile and downstream fining. For these simulations, all other model parameters were held constant. Though the objective of the modeling was not to simulate any particular river, the results of several of the simulations are compared to the cases of the Mississippi River, USA and the Fly River, Papua New Guinea in terms of dimensionless reach-averaged profile concavity and downstream fining.

The second phase of simulations is designed to study the effects of various physical processes, for a single driving mechanism case. For these simulations, the case of a sea-level rise rate of $1 \mathrm{~mm} / \mathrm{yr}$ was chosen. The physical processes investigated include the relative importance of bedload versus suspended load sorting, the effect of the 
active width, the importance of the loss of sediment to overbank deposition, and the effect of density stratification. Finally, a subsequent section investigates the sensitivity of the model to two specified model parameters.

\section{Model preliminaries}

\subsection{Generic study reach}

The objective of the model applications is to explore the development of downstream fining in large, low-slope, sand-bed rivers in response to various forcing mechanisms. Therefore a reach of river with parameters typical of large sand-bed rivers flowing into the ocean was constructed for application of the model. The reach is based loosely on several datasets on sand-bed rivers and hydraulic geometry relations (ASCE, in press).

The study reach has a bankfull discharge of $10,000 \mathrm{~m}^{3} / \mathrm{s}$, and bankfull channel width equal to $500 \mathrm{~m}$. The initial bed slope is constant and equal to $8 \times 10^{-5}$, and the total initial reach length is $500 \mathrm{~km}$. There are no tributaries entering the reach, so that the discharge and width are constant. The initial bed elevations are set so that a water surface elevation of zero at the downstream end corresponds to uniform flow. The initial bed and water surface profiles are shown in Figure 1, where the flow is uniform with a constant depth of $12.3 \mathrm{~m}$. The bed sediment (active layer) grain-size distribution is initially constant over the reach and log-normally distributed with median diameter of 0.4 $\mathrm{mm}$, and geometric standard deviation equal to 1.7. For all model runs the incoming sediment load and grain size distribution are constant in time and equal to those associated with the initial transport capacity at the upstream end. The size distributions of the initial bed material and incoming sediment load are shown in Figure 2. The total concentration of the incoming bed material load is $131 \mathrm{mg} / \mathrm{L}$.

The model accounts only for conservation of bed material load, and ascribes no role for wash load except for the implicit assumption that floodplain construction can keep pace with channel bed aggradation. While the cutoff size between bed material load and wash load is known to be a dynamic variable (e.g. Paola and Parker, 2000), for simplicity a cutoff size of $0.0625 \mathrm{~mm}$ is used here (e.g. Raudkivi, 1976). With this in mind, the bed material load in the present model consists entirely of sand. 
The slope of the delta face (foreset) was set to $5 \%$ which is within the range of typical foreset slopes for a sand delta (Borland, 1971; Kostic et al., 2002). The bottomset slope was given a value of $0.1 \%$, i.e. a value that is reasonably typical of the continental shelf on passive margins such as the Atlantic margin of the USA, the margin of the northern Gulf of Mexico and that of the Gulf of Papua, (e.g. Harris, 1994; O'Grady, 2001).

For all of the simulations performed, the reach was broken into 21 computational points, the grain-size distribution was discretized into 50 size intervals, and a time step of 100 years was used. This large time step was made possible by the use of the flow intermittency factor and the fully coupled, implicit numerical scheme.

\subsection{Active width}

The active width has been introduced to account for the fact that the river may aggrade over a width greater than just the channel width, such as the meander-belt width. Lateral migration dictates that the channel will move back and forth across the meanderbelt width, resulting in aggradation over this entire width over the long time periods considered here. The active width provides a simple method for accounting for this process. The model does not account for rapid aggradation and avulsion, a process that may result in aggradation over the entire floodplain width (if it is greater than a single meander-belt width) over long time periods. For the majority of the simulations presented, the active width has been set to ten times the channel width, which may correspond roughly to a meander belt width for most rivers. Also, simulations were performed for a range of active widths, from one channel width to twenty channel widths, to study the effects on downstream fining.

In point of fact, most of the sediment depositing within the meander belt or floodplain can be expected to be in the range that is here considered to be wash load, i.e. material finer than $0.0625 \mathrm{~mm}$. A detailed accounting of wash load routing and floodplain formation is beyond the scope of the present analysis. Implicit in the present

analysis is the assumption that the rate of aggradation of the channel bed is sufficiently slow so that floodplain construction can keep up with it without major planform instabilities. 


\section{Results I: Driving mechanisms}

\subsection{Prograding delta}

The first mechanism to be studied which drives downstream fining is the delta prograding into standing water. The prograding delta sets up a backwater profile which induces aggradation and leads to a concave upward profile, size selective transport, and downstream fining. For this simulation, sea-level rise and subsidence are both zero. The results are presented in Figures 3, 4, and 5, which show the longitudinal profile, downstream variation in median bed sediment $\left(D_{50}\right)$, and bed slope $\left(S_{o}\right)$, respectively, at times 500, 2000 and 5000 years. The downstream fining develops in the first 3000 years or so and persists for the remainder of the simulation $(10,000$ years total). Figure 4 indicates that after 5,000 years of simulation time, the $D_{50}$ of the bed decreases from 0.40 $\mathrm{mm}$ at the upstream end to $0.32 \mathrm{~mm}$ at the downstream boundary. This fining is accompanied by a decrease in bed slope (i.e. an upward concave profile) from $8.2 \times 10^{-5}$ at the upstream end to $6.4 \times 10^{-5}$ at the downstream boundary.

\subsection{Sea-level rise}

Another mechanism which leads to aggradation and downstream fining is sealevel rise. Sea-level rise was modeled by increasing the downstream water surface elevation $\xi$ of standing water into which the river flows. It was desired to approximate eustatic sea-level rise rates typical of the gradual rates of the past 5,000 years. The model here is designed to simulate slow aggradation and a single-thread meandering profile, conditions more typical of the late Holocene. Thus a range of sea-level rise rates up to a maximum of 2 mm/yr (e.g. Bard et al. 1990, Milne et al. 2002, Aslan and Autin 1999) were simulated for a 5,000 year time period.

The results of the sea-level rise simulations are presented in Figures 6, 7, and 8. The figures show the results after 5,000 years for the longitudinal profile and downstream variation in $D_{50}$ and $S_{o}$, respectively, for several rates of sea-level rise. Note that the case of zero sea-level rise corresponds to the case of delta progradation only presented in the

previous section. As expected, the degree of profile concavity and downstream fining increase with increasing sea-level rise. For example, for the $2 \mathrm{~mm} / \mathrm{yr}$ case $D_{50}$ decreases 
from $0.40 \mathrm{~mm}$ upstream to $0.19 \mathrm{~mm}$ at the downstream boundary, while for the 0.5 $\mathrm{mm} / \mathrm{yr}$ case $D_{50}$ is reduced to $0.28 \mathrm{~mm}$ at the downstream boundary. Similarly, for the 2 $\mathrm{mm} / \mathrm{yr}$ case $S_{o}$ decreases from $8.4 \times 10^{-5}$ upstream to $3.7 \times 10^{-5}$ at the downstream boundary, while for the $0.5 \mathrm{~mm} / \mathrm{yr}$ case $S_{o}$ is reduced from $8.2 \times 10^{-5}$ upstream to $5.8 \times 10^{-5}$ at the downstream boundary.

\subsection{Tectonic subsidence}

Tectonic subsidence has a similar effect as sea-level rise by creating space for aggradation, so that selective transport leads to downstream fining. A range of subsidence rates were simulated up to a maximum of $1 \mathrm{~mm} / \mathrm{yr}$ (i.e. the same range as that used by Paola et al. 1992), again for a 5000 year time period. For all simulations, subsidence was assumed constant (piston-style subsidence) over the reach. The simulation results (longitudinal profile, $D_{50}$, and $S_{o}$ ) are shown in Figures 9, 10, and 11. The results are quite similar to the sea-level rise results, in that the degree of concavity and downstream fining increase with increasing subsidence.

\subsection{Comparison with field cases}

The simulation results presented thus far provide a general comparison of three driving mechanisms for conditions typical of large, sand-bed rivers. It is also desired to provide a rough comparison of the model results with field cases, to see if the model predictions are the same order of magnitude as the field cases. To this end, the following reach-averaged, dimensionless measures of profile concavity $(P C)$ and downstream fining $(D F)$ are defined:

$$
\begin{gathered}
P C=\overline{H \frac{d^{2} \eta}{d x^{2}}} \\
D F=-\frac{\overline{d D_{50}}}{d x}
\end{gathered}
$$

where the overbar denotes averaging over the entire reach.

The profile concavity, $P C$, and downstream fining, $D F$, were computed for the simulation results presented in the previous sections and for the cases of the Mississippi and Fly Rivers, whose profiles and fining are shown in Figures 1 and 2 of the companion 
paper, Wright and Parker (submitted). These results are presented in Figures 12 and 13, which indicate that the degree of concavity and downstream fining of the simulations are of the same order of magnitude as the Mississippi and Fly. This provides confidence that a model of this type could be applied successfully to a particular field case. This has not been pursued here for a variety of reasons. First, the primary goal here is to develop the model and test it for simple cases. Also, as will be shown in the sensitivity analysis, the model is quite sensitive to a parameter which is not presently well constrained. Finally, application to a particular field case requires data that may not be available for most rivers, such as the initial longitudinal profile (e.g. at the transition from braiding to meandering) and incoming sediment load throughout the Holocene.

\section{Results II: Importance of other mechanisms}

\subsection{Bed load versus suspended load}

Large, sand-bed rivers tend to transport the majority of their sediment load in suspension. However, both bed load and suspended load result in size selective transport and thus will contribute to downstream fining. For bed load, the Ashida and Michiue (1972) relation introduces size selective transport through a dependence of the critical shear stress on particle diameter. Suspended load results in size selective transport through the near-bed concentration predictor and, more importantly, because smaller sizes have lower settling velocities and thus are transported at a higher rate that their larger brethren once in suspension. This is illustrated in Figure 14, where the initial size distributions of the bed, suspended, and total bed material loads are shown (bed load accounts for about $12 \%$ of total load). The bed load distribution is nearly identical to the initial bed material distribution (Figure 2) indicating that bed load sorting should be relatively weak. This is because the sorting effects come through the critical shear stress, which is much smaller than the total stress for bankfull conditions leading to near equal mobility conditions.

To illustrate how bed load and suspended load contribute to the overall amount of downstream fining, simulations were performed with and without bed load. The case of $1 \mathrm{~mm} / \mathrm{yr}$ sea-level rise and an active width equal to ten channel widths was used. Figure 15 shows the $D_{50}$ profiles at 5,000 years of simulation time. The results show that the 
bed load retards the fining that would develop due to suspended load sorting only. This is expected given the distributions of Figure 14. The bed load contributes a distribution roughly equivalent to the bed material, thus decreasing the overall size selectivity of the total load. The overall fining, as measured by (22), is approximately $10 \%$ greater with bed load excluded from the simulation.

\subsection{Active width}

The active width is defined here as the width over which channel-driven aggradation takes place. It is included in recognition that aggradation may occur over a width greater than the channel width only as the river migrates over its floodplain (e.g. Howard, 1992). For a meandering river, channel-driven aggradation (i.e. aggradation driven by the sediment transport divergence based on channel hydraulics, as opposed to overbank floodplain deposition) may take place over the entire meander-belt width. As the channel migrates back and forth across the meander-belt and aggrades, the elevation of the entire width of the meander-belt is raised. The active width can also account for a river occupying a multitude of positions through time. For example, the Mississippi River is known to have occupied five separate meander-belts during the Holocene (Aslan and Autin 1999). Thus the total amount of channel-driven aggradation would be distributed over the entire width of the five meander-belt widths.

For the simulation results presented thus far, the active width was set equal to ten channel widths. This may be considered a typical meander-belt width for a large, sandbed river. The sensitivity of the results is investigated here by assigning the active width values of one, five, ten, and twenty channel widths. Again, the case of $1 \mathrm{~mm} / \mathrm{yr}$ sea-level rise is used for illustration. The longitudinal profiles and downstream fining profiles for the four widths are shown in Figures 16 and 17, respectively. The figures illustrate the dramatic effect that the active width has on the results. For an active width equal to one channel width, the amount of aggradation is much greater and would almost certainly result in avulsion, which this model is not equipped to handle. Also for this case, the aggradation easily keeps pace with the sea-level rise, leading to less downstream decrease in slope and thus less downstream fining. The remaining simulations illustrate the increase in fining with increasing active width. This is because the greater width results 
in less aggradation, creating a stronger backwater effect as sea-level rises. The greater decrease in slope in the downstream direction with increasing active width accentuate size selective transport and result in greater downstream fining.

\subsection{Overbank sediment loss}

Though the model in its current state treats channel processes only, a rough estimate of the effects of the loss of sediment overbank can be made. The sediment sizes lost overbank will be highly biased to the finer sizes, as these are the sizes that ride highest in the water column. Thus overbank processes may be expected to decrease the overall downstream fining by removing these finer sizes. To make a very rough estimate of this effect without treating overbank processes in detail, a simulation was performed where it was assumed that all sediment in the upper ten percent of the flow depth was lost to the floodplain. Clearly this is not the case in reality, however, it is a conservative assumption that allows of an order of magnitude estimate of the effect of overbank sediment loss. The analysis is made possible by the use of the Wright and Parker (in press b) suspended sediment predictor, which treats the details of the vertical concentration profile using a modified Rouse formulation.

The size distributions of the bed-material sediment in the upper ten percent of the flow and over the entire flow depth are compared in Figure 18. This illustrates that the upper ten percent is dominated by finer sizes. In terms of transport rates, the upper ten percent accounts for only about three percent of the total transport. Simulations using 1 $\mathrm{mm} / \mathrm{yr}$ sea-level rise and an active width equal to ten channel widths, with and without overbank loss, yielded very slight differences in downstream fining. Reach-averaged fining rates from (22) differed by only about one percent, indicating that the loss of sediment overbank is not a primary controlling process in downstream fining. However, this should be considered a first order estimate, given the simplicity of the method used in the evaluation. While the method does account for the loss of the finer sizes, it does not account for relative differences in this loss in the downstream direction, which may be the most important factor. For example, an attenuating floodwave may result in longer periods of overbank flow in downstream reaches and thus more sediment lost to the floodplain (Y. Cui, personal communication). More definitive results on the effect of 
overbank processes await a model with a more complex treatment of channel-floodplain interaction.

\subsection{Slope of the bottomset}

For the model applications presented thus far the bottomset slope, $S_{b s}$ in Figure 3 of the companion paper, was set to $0.1 \%$, a slope representative of the continental shelf. The bottomset slope affects the progradation rate and shape of the delta. To investigate its effect on downstream fining, simulations were also performed with bottomset slopes of $1 \%$ and $0.03 \%\left(5 \times 10^{-4}\right)$. The $1 \%$ slope is representative of a steeper shelf slope, while the $0.03 \%$ slope is meant to represent flow into an estuary or reservoir where the bottomset slope would be mild. Again, the base case of $1 \mathrm{~mm} / \mathrm{year}$ sea-level rise, no subsidence, and an active width of ten channel widths was used. The resulting longitudinal profiles and downstream fining are shown in Figures 19 and 20, respectively. As the slope of the bottomset decreases, there is less space for deposition on the foreset delta face. Thus for the lower bottomset slopes the delta progrades faster and the elevation of the topset-foreset break is lower in elevation. This results in a greater backwater effect, greater downstream decreases in slope (increased concavity) and sediment transport capacity, and greater downstream fining (Figure 20).

\subsection{Density stratification}

The formulations used for hydraulic resistance and suspended-sediment transport rate include the effects of density stratification, which have been shown to be particularly important for large, low-slope, sand-bed rivers (Wright and Parker, in press a, b). The density gradient resulting from the vertical concentration gradient induces a buoyancy force which inhibits turbulent mixing. Wright and Parker (in press a) showed that the reduction in turbulent mixing results in decreased sediment transport (less upward vertical flux of sediment) and decreased median size of the suspension (greatest effect is on largest sizes since they have largest concentration gradients), as opposed to the without stratification case.

To test the effects of density stratification on model predictions of downstream fining, a simulation was performed with the stratification effects removed from the 
hydraulic resistance and suspended-sediment transport relations. Again, the case of 1 $\mathrm{mm} / \mathrm{yr}$ sea-level rise and an active width equal to ten channel widths was used. Without stratification, the uniform flow depth increases from $12.3 \mathrm{~m}$ to $14.7 \mathrm{~m}$, the sediment transport capacity of the reach increases from $132 \mathrm{mg} / \mathrm{L}$ to $161 \mathrm{mg} / \mathrm{L}$, and the median size of the transported sediment increases from $0.167 \mathrm{~mm}$ to $0.176 \mathrm{~mm}$. These changes affect the initial and boundary conditions because the initial condition is uniform flow and the incoming sediment load is set to the capacity at the most upstream point. The resulting longitudinal profiles and downstream variations in bed $D_{50}$ are shown in Figures 21 and 22. The increased incoming load results in increased aggradation and delta progradation, but the effects on downstream fining are not great. This is because density stratification has a greater effect on the total suspended-sediment transport rate than on the grain-size distribution of the suspension.

\section{Sensitivity analysis}

The model formulation contains many empirical parameters which must be specified. The sediment transport and hydraulic resistance relations, for example, contain several parameters which were determined from field and laboratory data. It is not the goal here to study these parameters, as they are better constrained by data than some other parameters. The two parameters chosen for study here are the two considered to be the least constrained by data or theory. They are the active layer thickness, $L_{a}$, and the relation for partitioning sediment at the interface between the active layer and the substrate during aggradation, $F_{I k}$.

During aggradation, sediment is transferred from the active layer to the underlying substrate. The formulation presented in the companion paper partitions this sediment between the transported material $\left(F_{t k}\right)$ and the material in the active layer $\left(F_{b k}\right)$ :

$$
F_{I k}=c F_{t k}+(1-c) F_{b k}
$$

The only experimental evaluation of the partitioning constant, $c$, is that of Toro-Escobar, et al. (1996), who found $c=0.7$ for laboratory experiments of downstream fining of gravels. The weighting of the interface fraction toward the transported material was attributed to a sieving mechanism whereby finer material in transport moves directly through the active layer to the substrate. For sand beds, there are no experimental results 
to provide guidance. Here the choice of $c=0$ was adopted for all model simulations because the sieving mechanism is expected to be greatly hindered in a sand-bed river versus a gravel bed because 1) the bed material grain-size distribution is more narrow and, 2) the active layer thickness is significantly larger (one dune height vs. $D_{90}$ ). This choice dictates that during aggradation, only material from the active layer is transferred to the substrate.

To test the sensitivity of the model to this partitioning, $c$ was varied between $O$ and 0.7 , i.e. the gravel case was considered a maximum value for $c$. The case of $1 \mathrm{~mm} / \mathrm{yr}$ sea-level rise was again used as the base case. The results, in terms of the fining measure defined in (2), are shown in Figure 23. In the figure, $D F_{o}$ is the fining rate for the base case of $c=0$. The results indicate that the partitioning of sediment at the active layer/substrate interface can have a significant effect on the degree of downstream fining predicted by the model. The choice of $c=0$, which transfers active layer sediment only to the substrate during aggradation, results in the greatest downstream fining. The choice $c=0.7$, which has been found experimentally for gravels, yields approximately one-half the amount of downstream fining as compared to $c=0$. This type of sensitivity to a parameter that is not very well constrained by data makes application of the model to a particular field case difficult. Model results could most likely be made to match the field data simply by adjusting $c$. Thus there is a clear need for further experimental and theoretical research into bed sediment mixing mechanics, whether it be to better constrain a parameter such as $c$ for sand-beds, or to support the probabilistic formulation for Exner recently presented by Parker et al. (2000). Recent progress in this area has been made by Blom (2003).

Several relations have been used by various authors for specifying the active layer thickness. Deigaard (1980) and Rahuel et al. (1989) assumed the thickness to be proportional to water depth, with a proportionality constant between 0.1 and 0.2 , suggesting that the active layer has a thickness of about a dune height for sand-bed rivers. This line of reasoning has been followed here, where $L_{a}$ was set equal to one dune height, with the height predicted by the Julien and Klaasen (1995) relation. The sensitivity of the model to the active layer thickness was tested by varying the thickness from one-half to twice the dune height. It was found that the model results are relatively insensitive to 
active layer thickness. The degree of downstream fining was found to vary by less than $1 \%$ from the base case of $L_{a}$ equal to one dune height.

\section{Conclusions}

The companion paper, Wright and Parker (submitted) presented a numerical model for the simulation of the simultaneous development of the longitudinal profile and bed sediment distribution in sand-bed rivers. This paper presents results from application of the model to a generic model reach designed to be representative of large, low-slope, sand-bed rivers. The results of the model simulations lead to the following observations and conclusions:

- A delta prograding into standing water at the downstream boundary leads to the development of a backwater profile. The resulting aggradation leads to a downstream decrease in slope (upward concave longitudinal profile), and size selective transport results in downstream fining of bed sediment.

- Sea-level rise and tectonic subsidence create space for aggradation, leading to increased profile concavity and downstream fining. The degree of concavity and fining increase with increasing sea-level rise and subsidence.

- The degree of dimensionless, reach-averaged, profile concavity and downstream fining predicted by the model for the generic large, sand-bed river are of the same order of magnitude as the Mississippi and Fly Rivers, for sea-level rise and subsidence rates typical of the late Holocene.

- $\quad$ Size selective transport due to the suspended load dominates the sorting process compared to bed load.

- The width over which aggradation occurs, termed the active width here, has a significant effect on the model results. An active width of one channel width leads to rapid aggradation which would most likely lead to avulsion, which the model is not equipped to handle. Active widths typical of meander belt widths (i.e. about ten channel widths) lead to significantly less aggradation and greater downstream fining. This is because as active width increases, sea-level rise and/or subsidence outpaces aggradation leading to a greater backwater effect and selective transport. 
- During overbank flows, the finest sizes in transport may be lost to floodplain deposition. A very crude analysis here indicates that this process has a minor effect on downstream fining. However, more definitive results on this effect await a more complex model of channel-floodplain interaction.

- The slope of the bottomset of the prograding delta can have a significant effect on the profile concavity and downstream fining. As the bottomset slope decreases, the degree of concavity and downstream fining increase.

- The model was shown to be quite sensitive to the size distribution of sediment transferred at the interface between the active layer and substrate as the bed aggrades. During aggradation, the sediment transferred to the substrate may be a mixture of the sediment in transport and the sediment in the active layer. This partitioning is not well constrained for sand transport. Further research into this process would significantly improve models of this type.

\section{Acknowledgements}

This material is based on work supported by the National Science Foundation under Agreement Number CTS-0096916, "Mechanics of downstream fining in long reaches of large, low-slope sand-bed rivers." In addition, this work was also supported in part by the STC program of the National Science Foundation under Agreement Number EAR-0120914. This paper is a publication of the National Center for Earth-surface Dynamics.

\section{References}

1. ASCE, in press. New Manual 54.

2. Ashida, K., and Michiue, M., 1972. "Study on hydraulic resistance and bedload transport rate in alluvial streams" Transactions, Japan Society of Civil Engineering 206, 59-69.

3. Aslan, A., and Autin, W.J., 1999. "Evolution of the Holocene Mississippi River floodplain, Ferriday, Louisiana: Insights on the origin of fine-grained floodplains" Journal of Sedimentary Research 69(4), 800-815. 
4. Bard, E.., Hamelin, B., and Fairbanks, R.G., 1990. "U-Th ages obtained by mass spectrometry in corals from Barbados: sea level during the past 130,000 years", Nature 346, 456-458.

5. Blom, A., 2003. "A vertical sorting model for rivers with non-uniform sediment and dunes", Ph.D. thesis, University of Twente, the Netherlands, 267 p.

6. Blum, M.D. and Tornqvist, T.E., 2000. "Fluvial responses to climate and sea-level change: a review and look forward", Sedimentology 47 (Suppl. 1), 2-48.

7. Borland, W.M., 1971. "Reservoir sedimentation" Chapter 25, River Mechanics, Shen, H.W., ed., H.W. Shen, Publisher., 29-1 - 29-24.

8. Deigaard, R., 1980. "Longitudinal and transverse sorting of grain sizes in alluvial rivers" Paper No. 26, Institute of Hydrodynamics and Hydraulic Engineering, Technical University of Denmark.

9. Harris, P. T., 1994. "Incised valleys and backstepping deltaic deposits in a foreland-basin setting, Torres Strait and Gulf of Papua, Australia" In SEPM Special Publication No. 51, Incised-valley Systems: Origin and Sedimentary Sequences, ISBN 1-56576-015-8, 99-107.

10. Howard, A.D., 1992. "Modelling channel migration and floodplain development in meandering streams" in Lowland Flood Plain Rivers, Carling, P.A. and Petts, G.E., eds., $1-41$.

11. Julien, P.Y., and Klaasen, G.J., 1995. "Sand-dune geometry of large rivers during floods." J. Hydraulic Eng., 121(9), 657-663.

12. Kostic, S., Parker, G. and Marr, J. G., 2002. "Role of turbidity currents in setting the foreset slope of clinoforms prograding into standing fresh water" $J$. Sedimentary Research, 72(3), 353-362.

13. Milne, G.A., Mitrovica, J.X., and Schrag, D.P., 2001. "Estimating past continental ice volume from sea-level data” Quaternary Science Reviews 21, 361-376.

14. O’Grady, D.B., 2001. "Sedimentary geomorphology of siliciclastic continental slopes" Ph.D thesis, University of Colorado, 189 p.

15. Paola, C. and Parker, G., 2000. "Criterion for cutoff size of bed material load versus wash load in sand bed streams" Eos Trans. AGU, 81 (48), Fall Meet. Suppl., Abstract H11C-29. 
16. Parker, G., Paola, C., and Leclair, S., 2000. "Probabilistic Exner sediment continuity equation for mixtures with no active layer" Journal of Hydraulic Engineering 126(11), 818-826.

17. Rahuel, J.L., Holly, F.M., Chollet, J.P., Belleudy, P.J., and Yang, G., 1989. "Modeling of riverbed evolution for bedload sediment mixtures" Journal of Hydraulic Engineering 115(11), 1521-1542.

18. Raudkivi, A.J., 1976. "Loose Boundary Hydraulics" Oxford, Pergamom Press, 397 p.

19. Toro-Escobar, C.M., Parker, G., and Paola, C., 1996. "Transfer function for the deposition of poorly sorted gravel in response to streambed aggradation" Journal of Hydraulic Research 34(1), 35-53.

20. Wright, S.A, and Parker, G., submitted. "Modeling downstream fining in sand-bed rivers I: formulation” Journal of Hydraulic Research.

\section{Notation}

c partitioning coefficient for active layer-substrate interface grain-size distribution

$D_{50} \quad$ median diameter of bed sediment [L]

$D_{90}$ diameter of which $90 \%$ of bed material is finer [L]

DF dimensionless, reach-averaged measure of downstream fining

$D F_{o} \quad$ dimensionless, reach-averaged measure of downstream fining for the case $\mathrm{c}=0$

$F_{b k} \quad$ fraction of bed sediment within grain-size interval $k$

$F_{I k} \quad$ fraction of sediment at active layer-substrate interface within grain-size interval $k$

$F_{t k} \quad$ fraction of grain-size interval $k$ in transport

$H \quad$ water depth [L]

$L_{a} \quad$ active layer thickness [L]

$P C$ dimensionless, reach-averaged measure of longitudinal profile concavity

$S_{b s} \quad$ bottomset slope [L/L]

$S_{o} \quad$ river bed slope $[\mathrm{L} / \mathrm{L}]$

$x \quad$ streamwise space coordinate [L]

$\eta \quad$ bed elevation [L]

$\xi$ elevation of standing water into which the river flows [L]. 


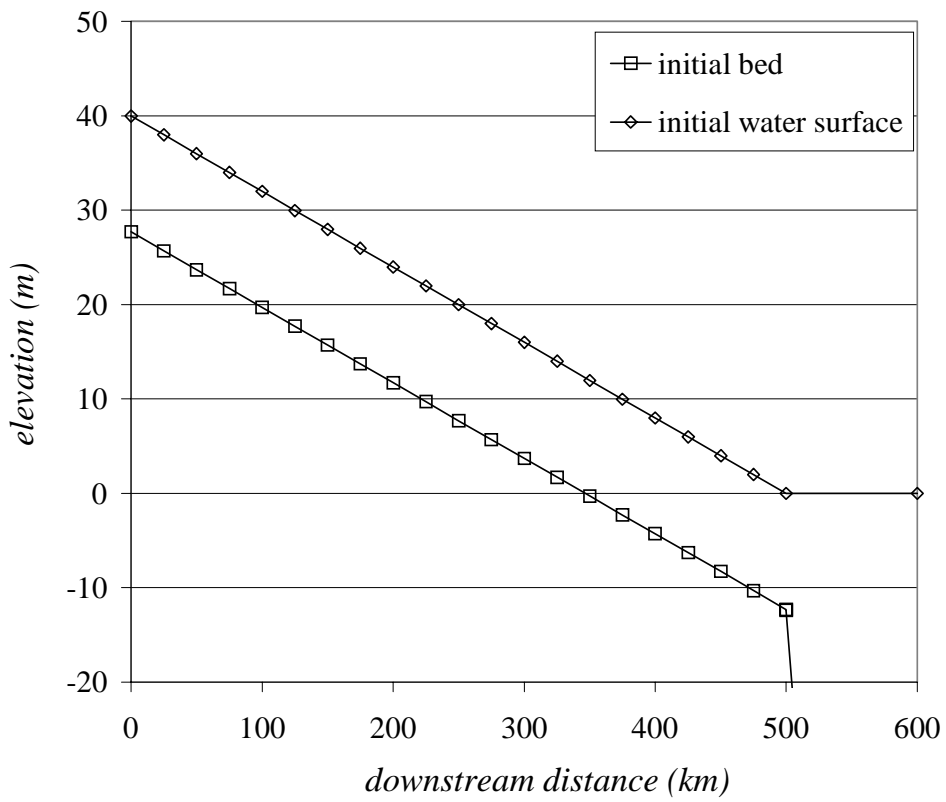

Figure 1 Initial bed and water surface elevation for all model runs.

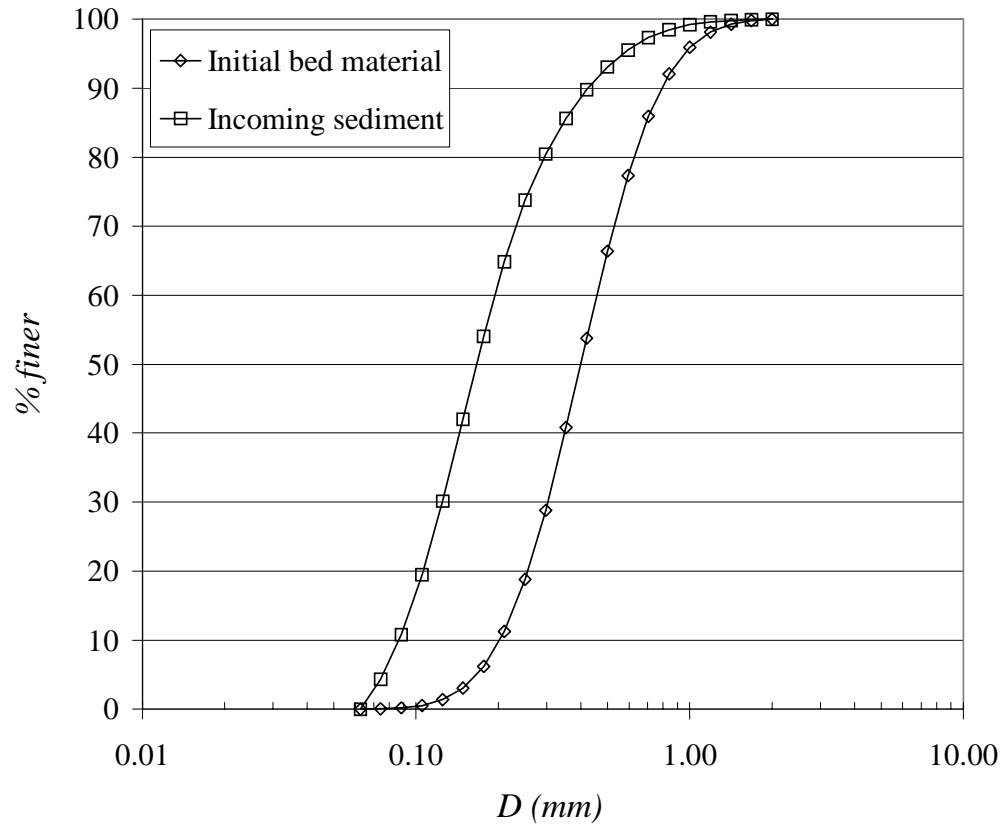

Figure 2 Initial bed material and incoming sediment grain-size distributions. The initial bed material distribution is constant throughout the reach. 


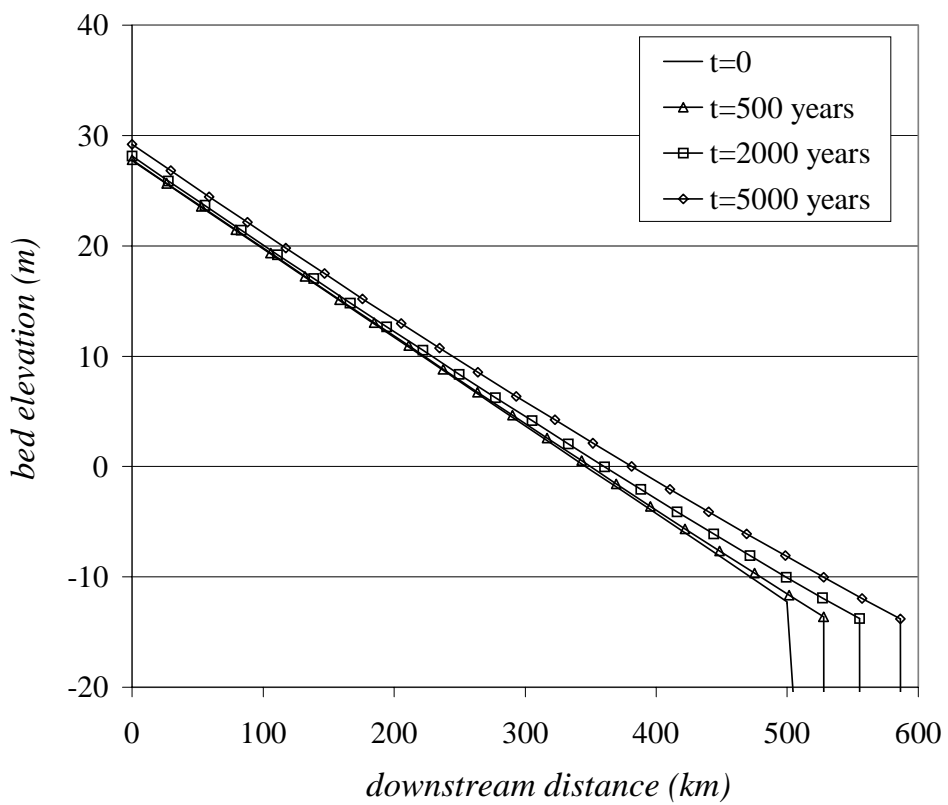

Figure 3 Simulated time evolution of the longitudinal profile for the case of delta progradation only.

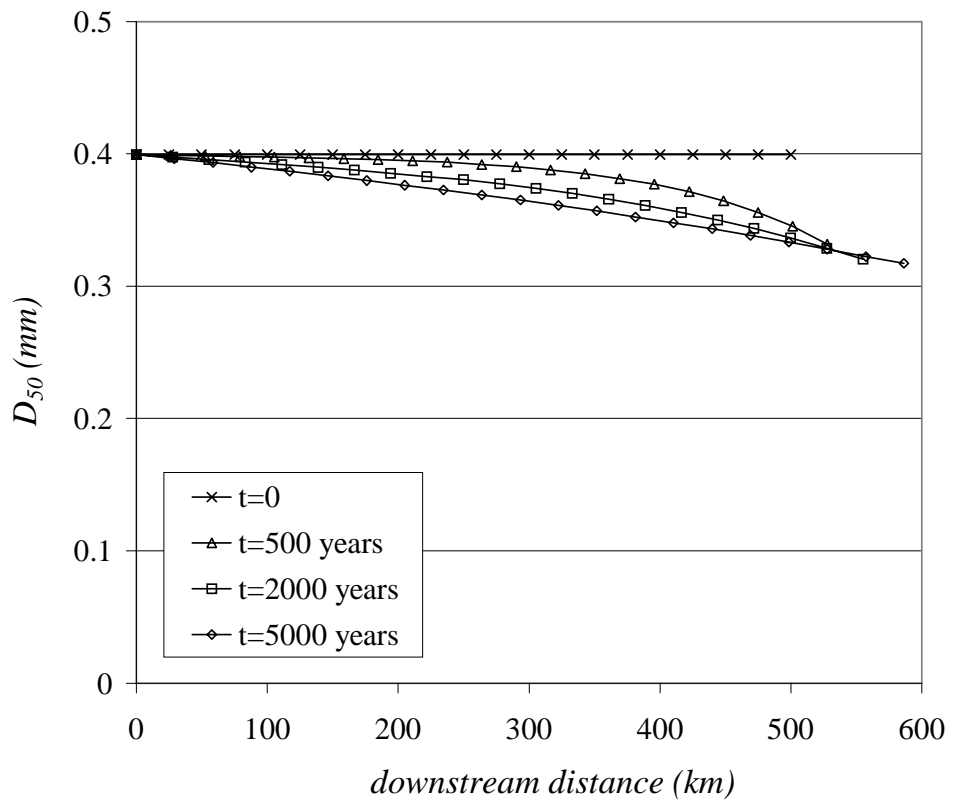

Figure 4 Simulated time evolution of the downstream variation in median bed sediment diameter for the case of delta progradation only. 


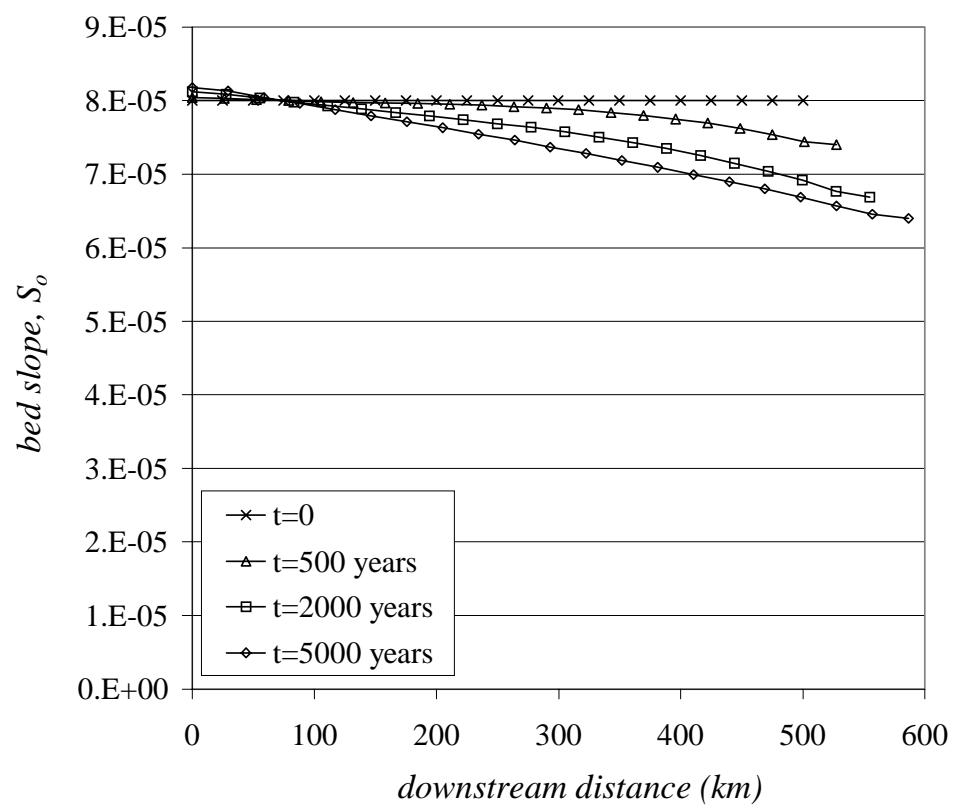

Figure 5 Simulated time evolution of the downstream variation in bed slope for the case of delta progradation only.

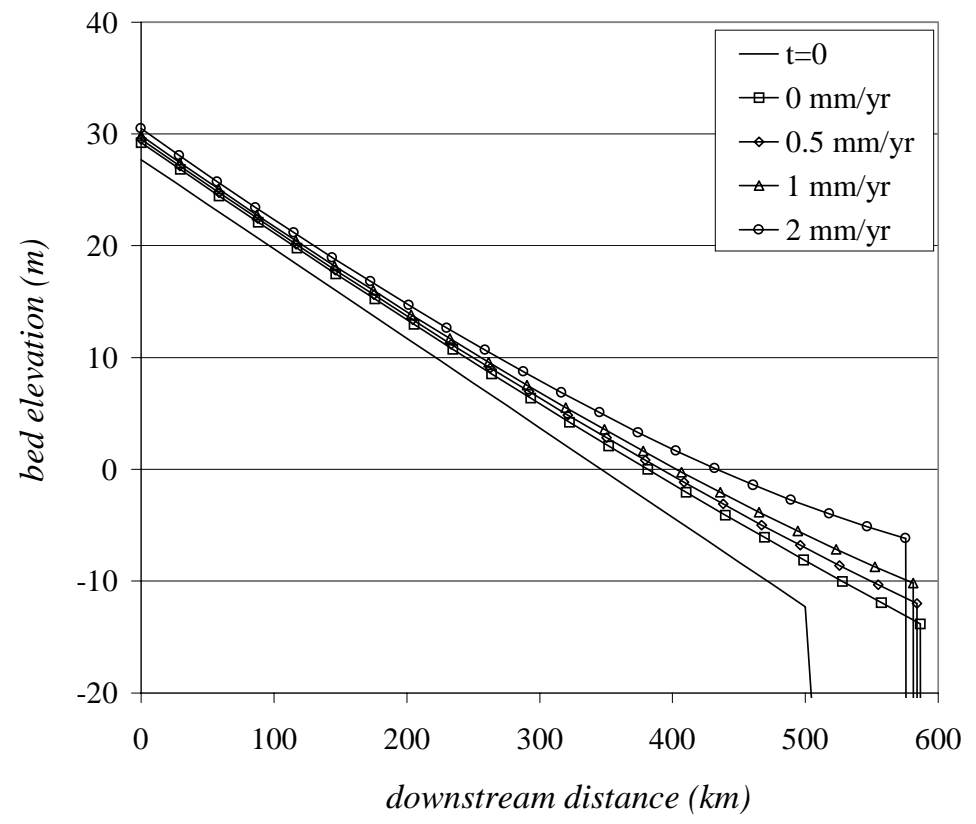

Figure 6 Simulated longitudinal profiles at $\mathrm{t}=5,000$ years for a range of rates of sealevel rise. 


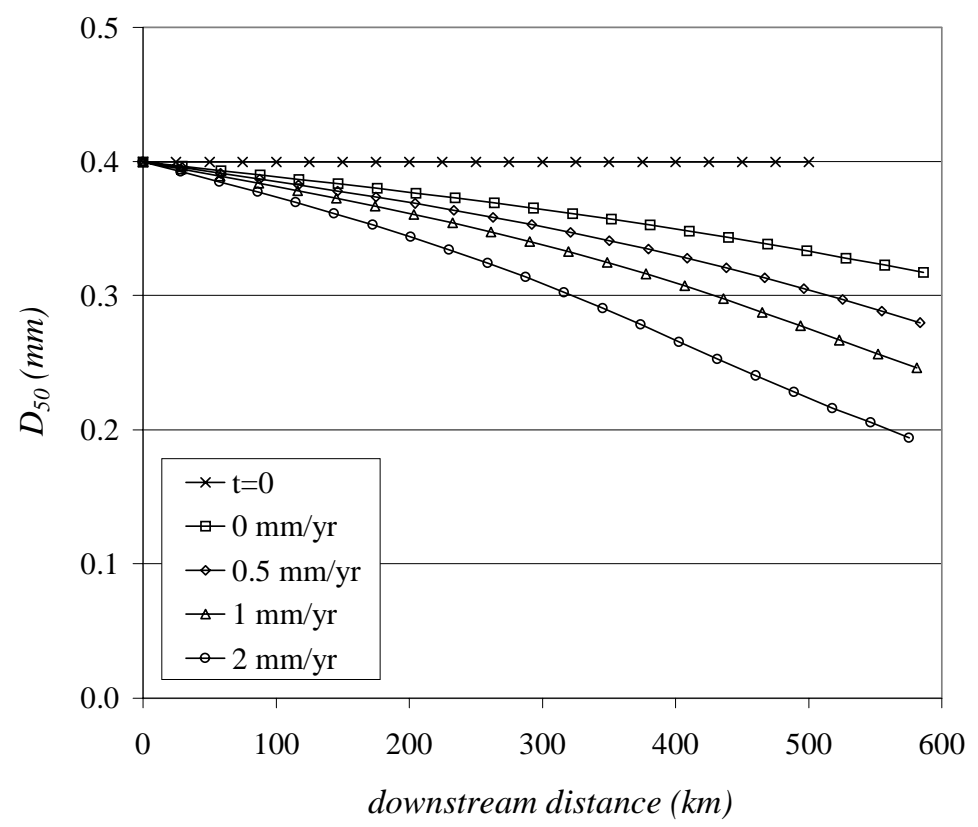

Figure 7 Simulated downstream variation in median bed sediment diameter at $\mathrm{t}=5,000$ years for a range of rates of sea-level rise.

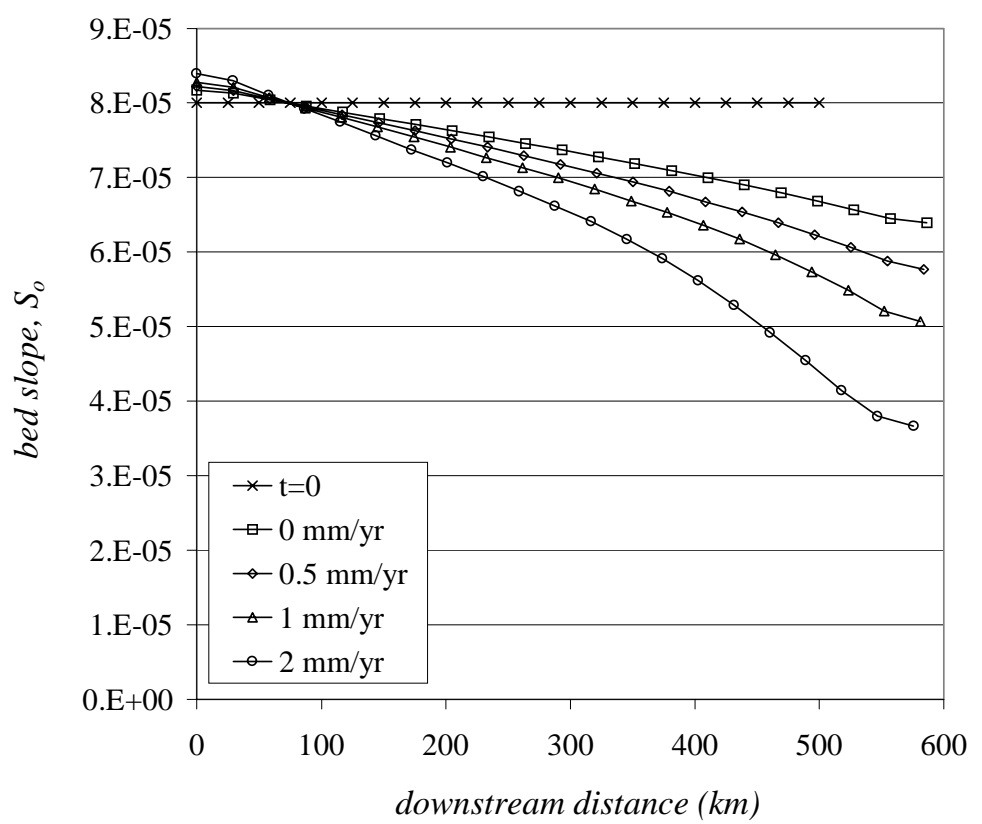

Figure 8 Simulated downstream variation in bed slope at $t=5,000$ years for a range of rates of sea-level rise. 


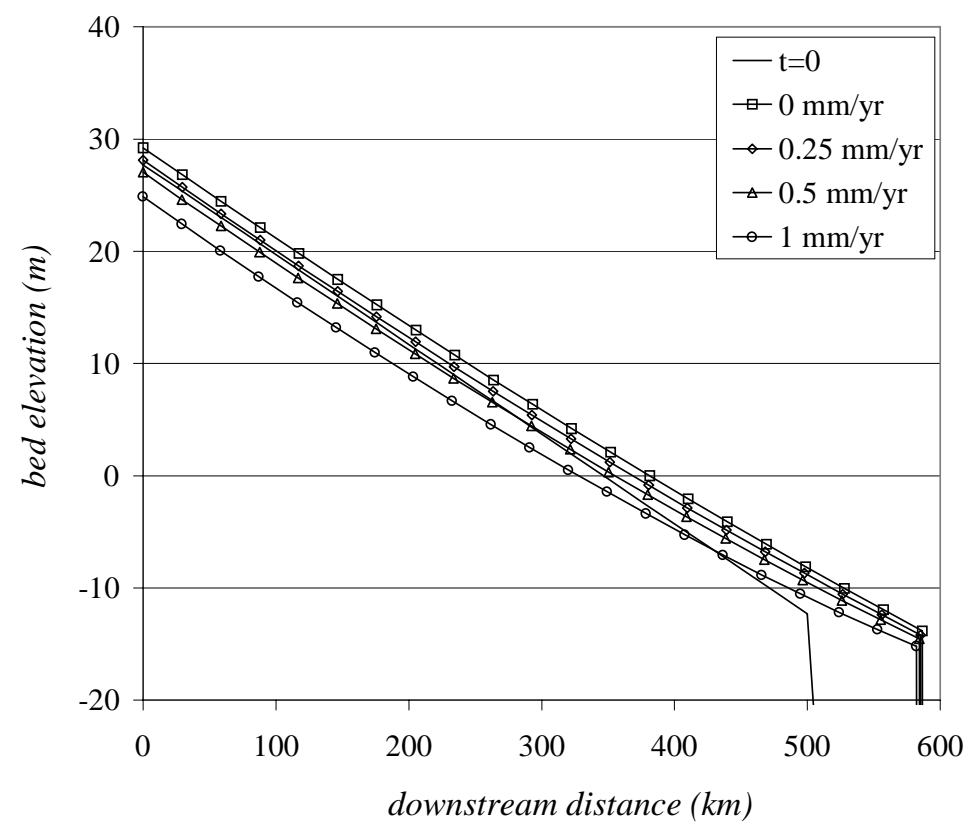

Figure 9 Simulated longitudinal profiles at $\mathrm{t}=5,000$ years for a range of subsidence rates.

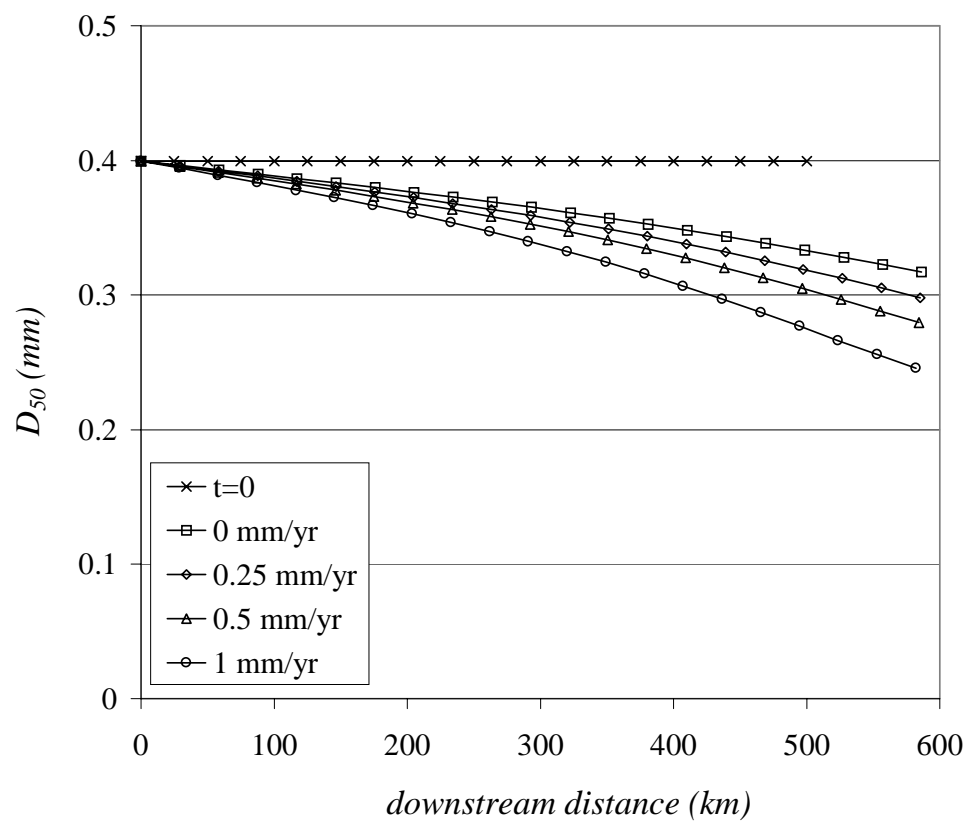

Figure 10 Simulated downstream variation in median bed sediment diameter at $\mathrm{t}=5,000$ years for a range of subsidence rates. 


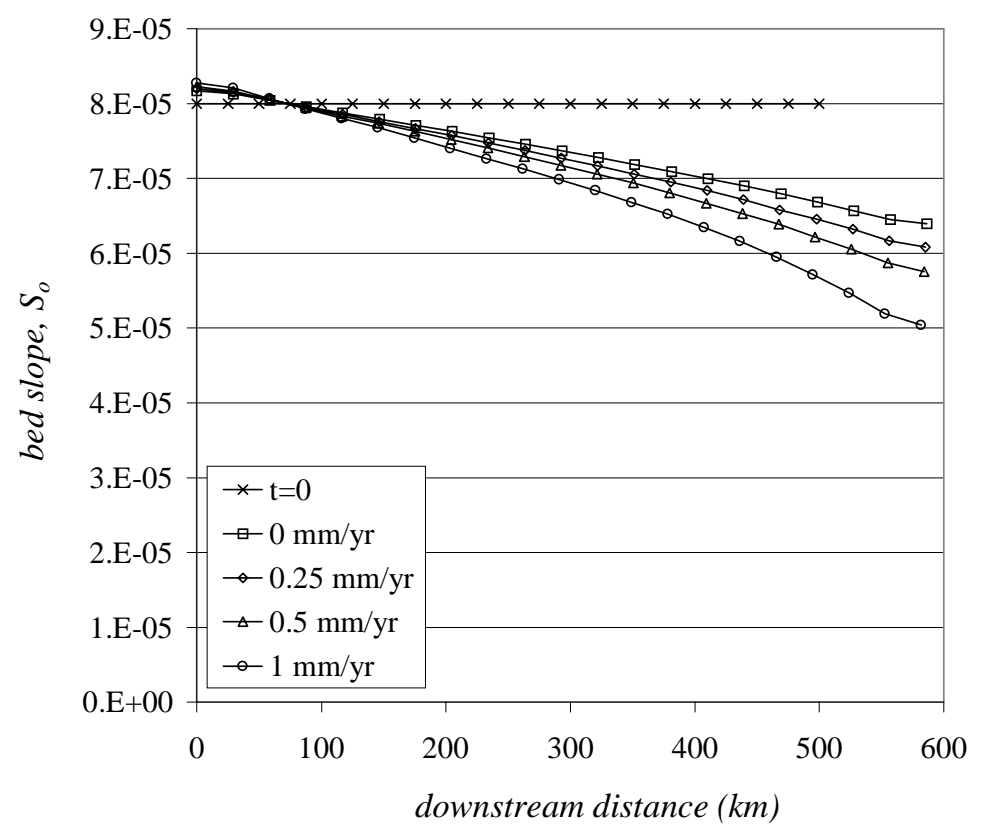

Figure 11 Simulated downstream variation in bed slope at $t=5,000$ years for a range of subsidence rates.

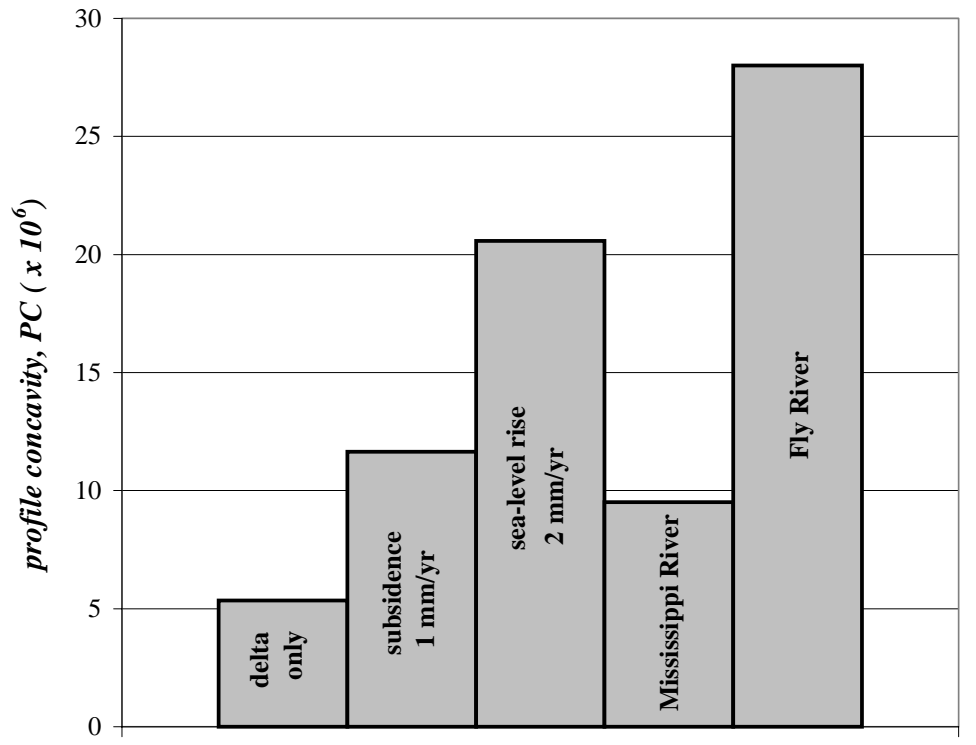

Figure 12 Comparison of dimensionless, reach-averaged, longitudinal profile concavity for several model simulations and the Mississippi and Fly Rivers. 


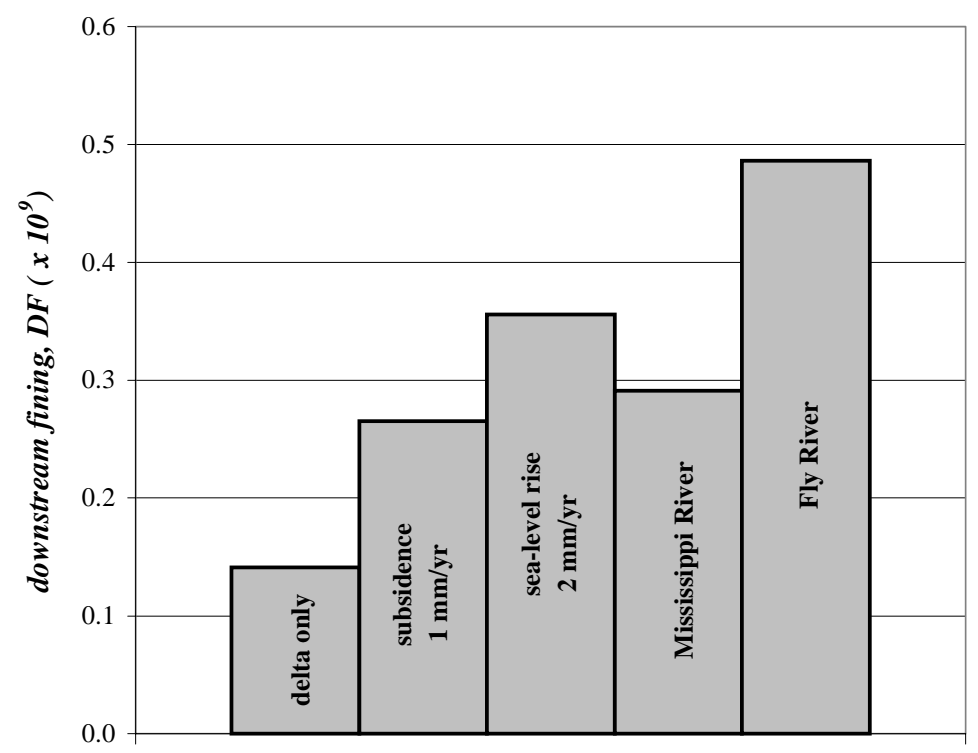

Figure 13 Comparison of dimensionless, reach-averaged, downstream fining for several model simulations and the Mississippi and Fly Rivers.

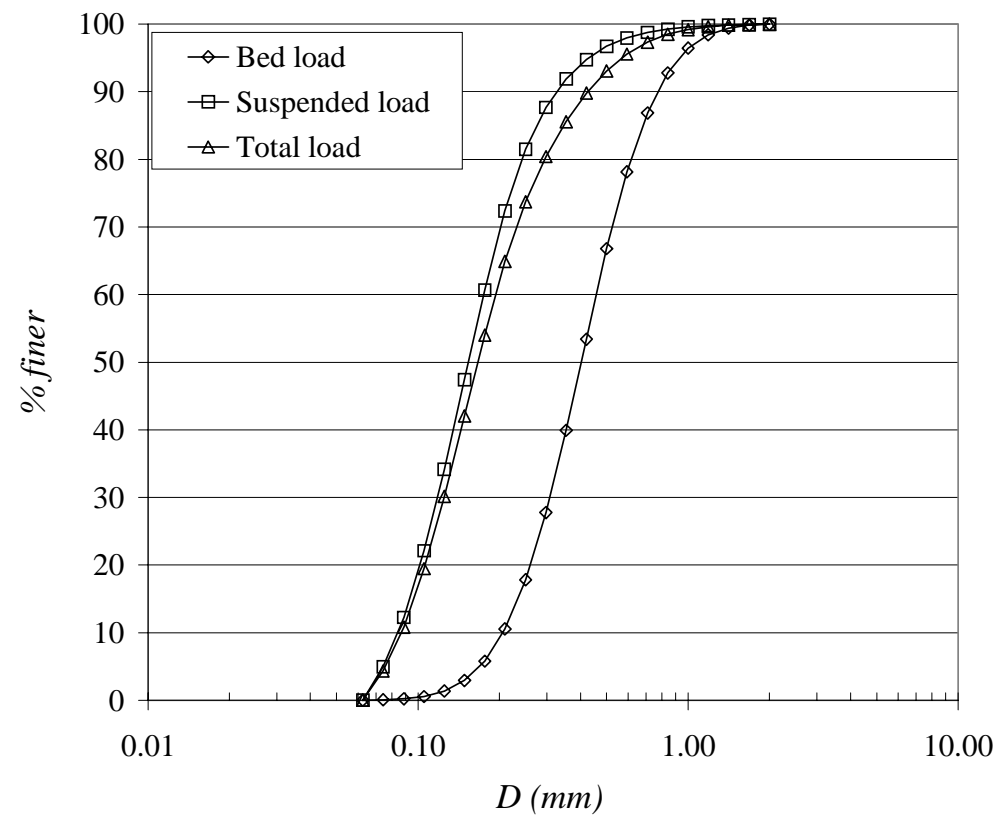

Figure 14 Grain-size distributions of the bed, suspended, and total loads throughout the reach at the initial condition. 


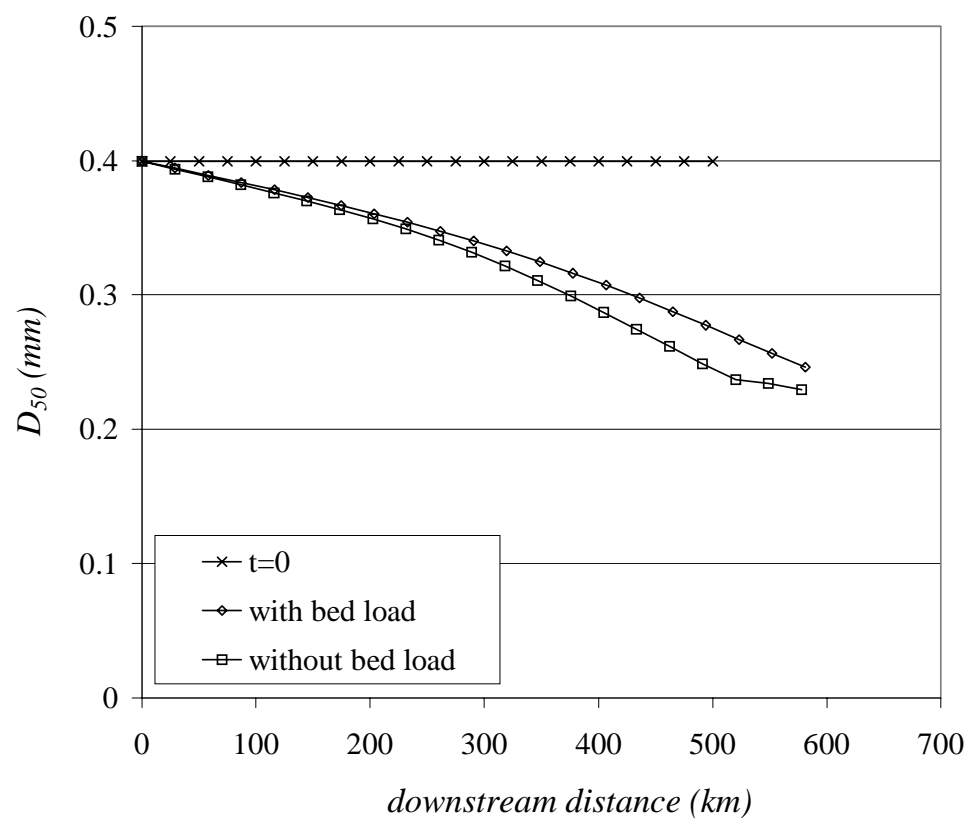

Figure 15 Simulated downstream variation in median bed sediment diameter at $t=5,000$ years for the case with and without bed load $(1 \mathrm{~mm} / \mathrm{year}$ sea-level rise, no subsidence).

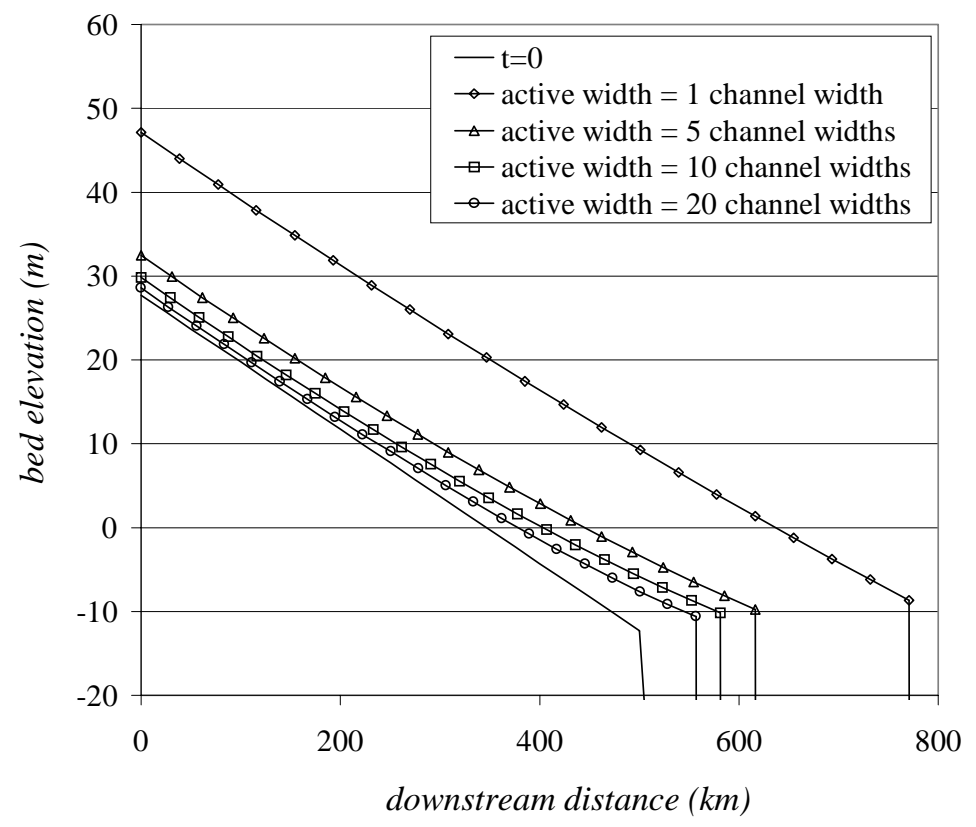

Figure 16 Simulated longitudinal profiles at $t=5,000$ years for a range of active widths (1 $\mathrm{mm}$ /year sea-level rise, no subsidence). 


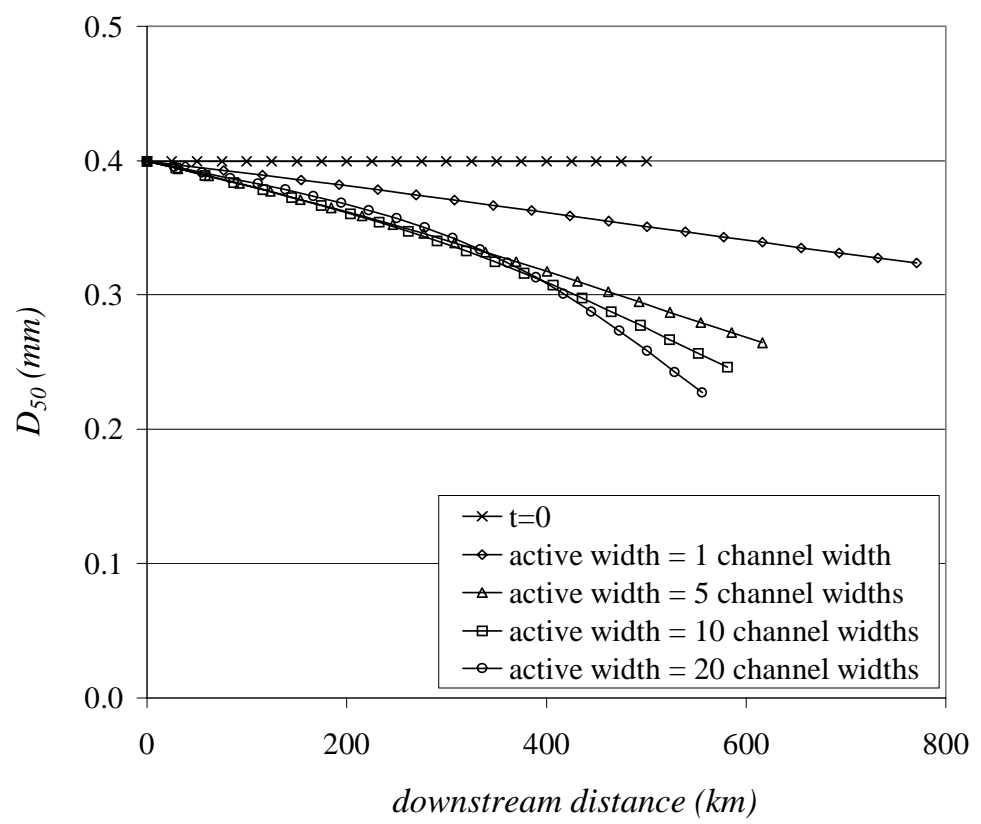

Figure 17 Simulated downstream variation in median bed sediment diameter at $\mathrm{t}=5,000$ years for a range of active widths ( $1 \mathrm{~mm} /$ year sea-level rise, no subsidence).

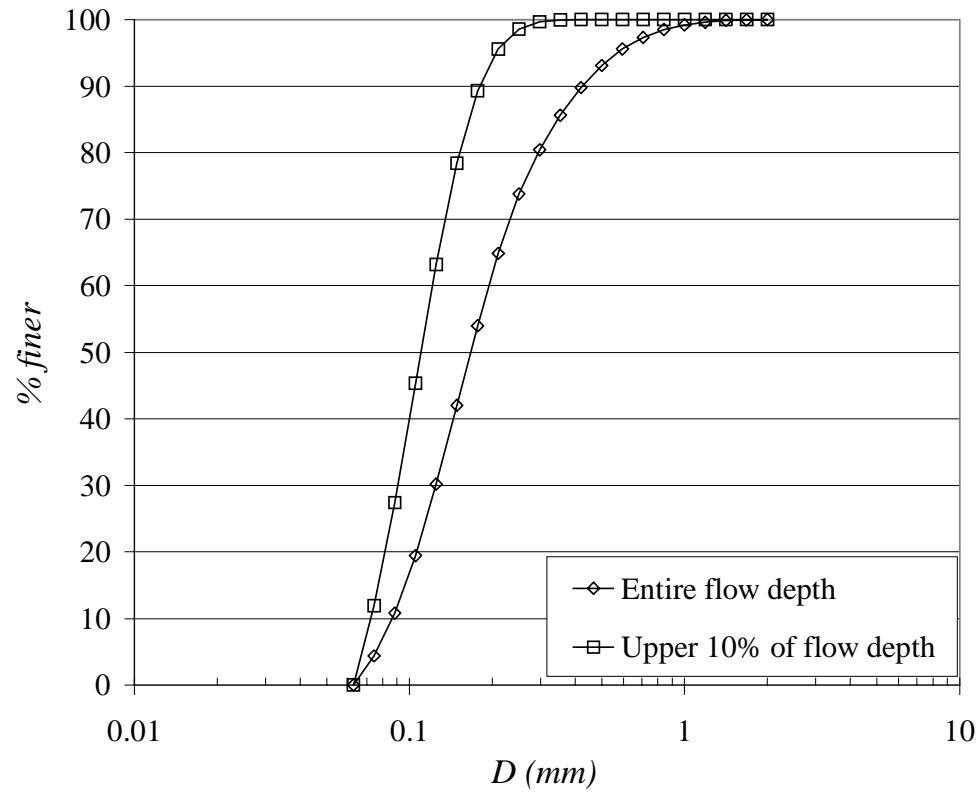

Figure 18 Grain-size distributions of suspended-sediment over the entire flow depth and over the upper ten percent of the flow depth. 


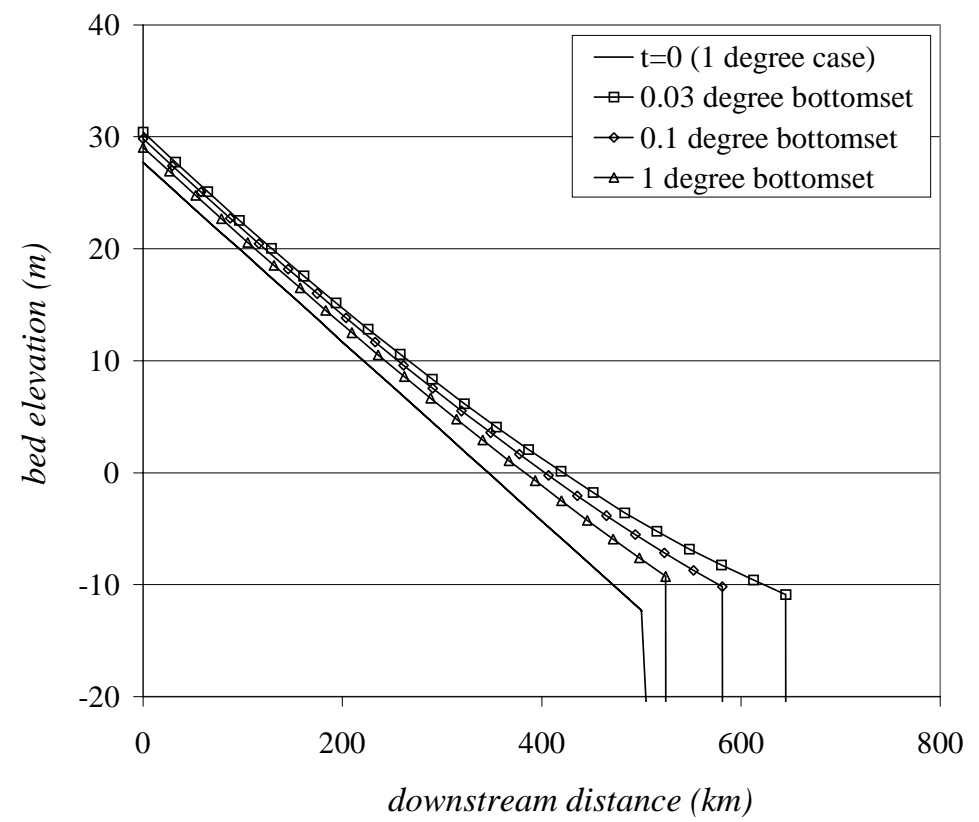

Figure 19 Simulated longitudinal profiles at $\mathrm{t}=5,000$ years for several bottomset slopes ( $1 \mathrm{~mm} /$ year sea-level rise, no subsidence).

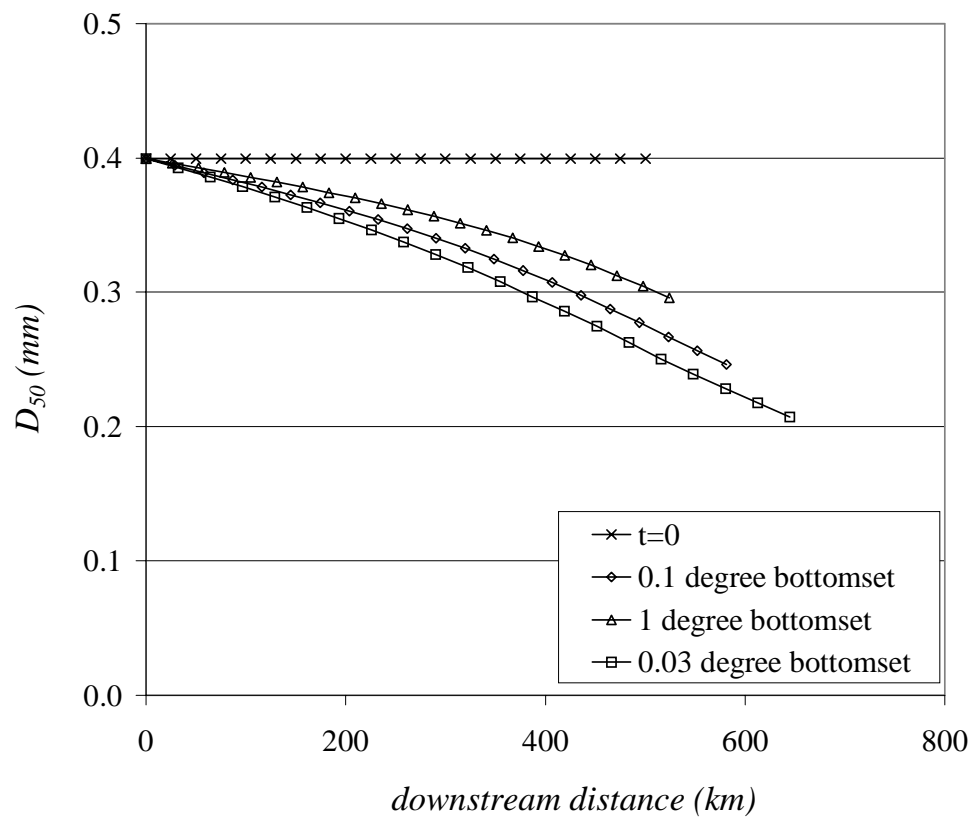

Figure 20 Simulated downstream variation in median bed sediment diameter at $\mathrm{t}=5,000$ years for several bottomset slopes ( $1 \mathrm{~mm} /$ year sea-level rise, no subsidence). 


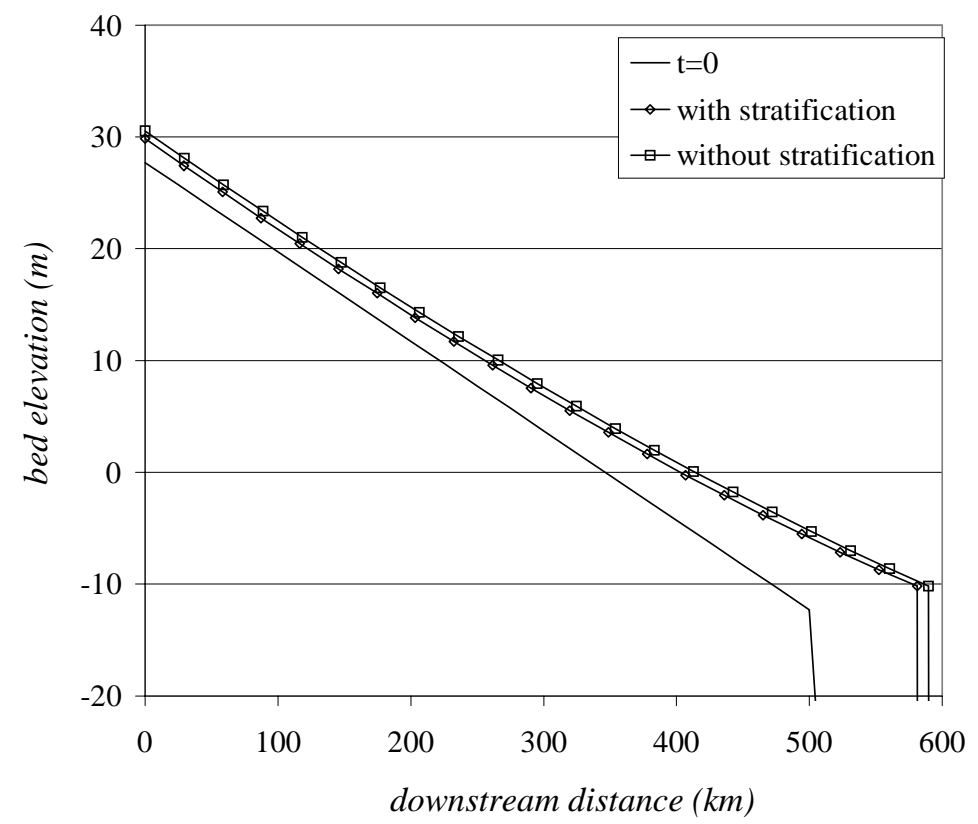

Figure 21 Simulated longitudinal profiles at $\mathrm{t}=5,000$ years for the cases with and without density stratification effects ( $1 \mathrm{~mm} /$ year sea-level rise, no subsidence).

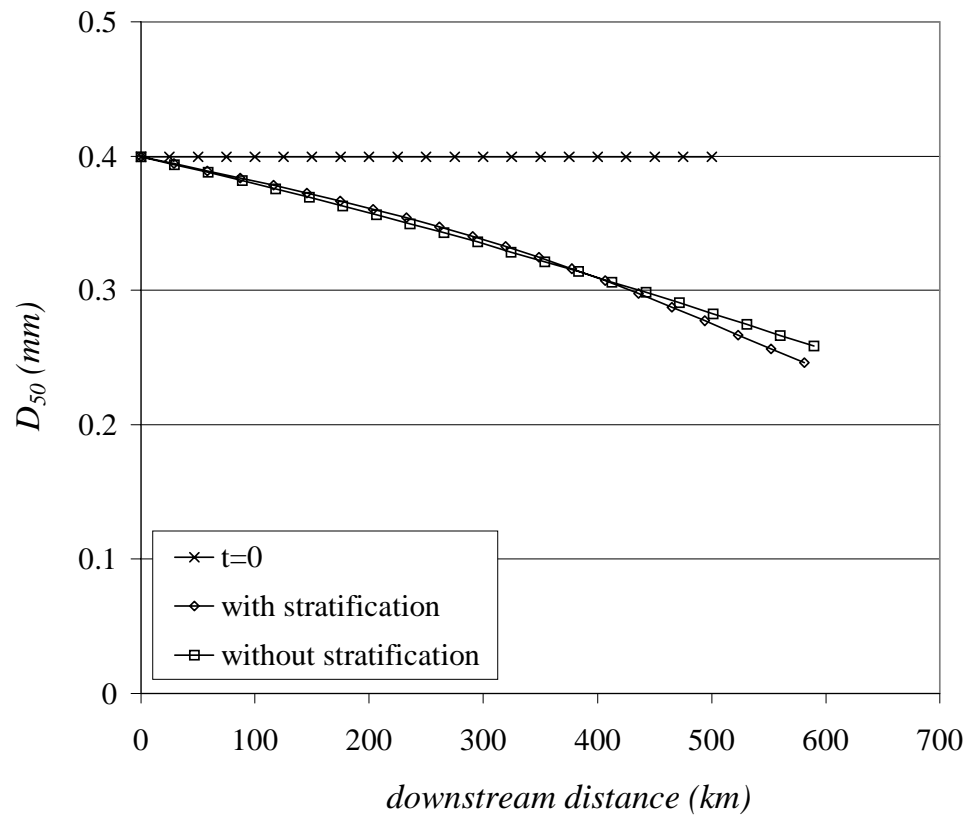

Figure 22 Simulated downstream variation in median bed sediment diameter at $\mathrm{t}=5,000$ years for the cases with and without density stratification effects $(1 \mathrm{~mm} / \mathrm{year}$ sea-level rise, no subsidence). 


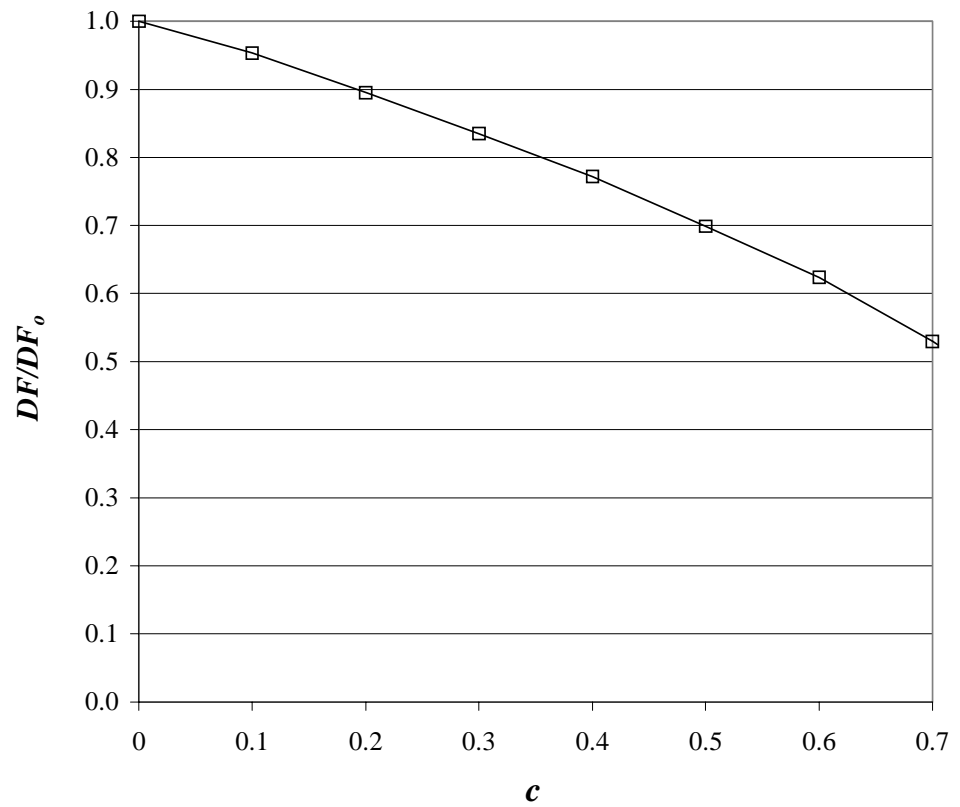

Figure 23 Effect of parameter $c$, which controls the partitioning of sediment between transported sediment and active layer sediment, on downstream fining (1 $\mathrm{mm} /$ year sea-level rise, no subsidence). $\quad D F$ is reach-averaged downstream fining; $D F_{o}$ is for the case $c=0$. 